\title{
Response of Vegetation to Extreme Climate Events Change in Typical Steppe in Inner Mongolia
}

\author{
Lina $^{1}$, Jiquan Zhang ${ }^{1}$, Risu $\mathrm{Na}^{2}$, Zhijun Tong ${ }^{1}$, Yin shan ${ }^{3}$ \\ 1School of Environment, Northeast Normal University, Changchun 130024, China \\ 2College of Geographical Science, Northeast Normal University, Changchun 130024, China \\ 3College of Geographical Science, Inner Mongolia Normal University, Huhhot 010022, China

\section{内蒙古典型草原区植被对极端气候事件的响应} \\ 丽娜 ${ }^{1}$, 张继权 ${ }^{1}$, 那日苏 ${ }^{2}$, 佟志军 ${ }^{1}$, 银山 ${ }^{3}$ \\ ${ }^{1}$ 东北师范大学环境学院, 长春 130024 , 中国 \\ 2 东北师大地理科学学院, 长春 130024 , 中国 \\ ${ }^{3}$ 内蒙古师范大学地理科学学院, 呼和浩特 010020 , 中国
}

\begin{abstract}
In this paper, the extreme climate index was extracted by using the RClimdex model and the Kriging spatial interpolation was applied to the extreme climate index from the 1982-2015 daily temperature and precipitation data of 19 meteorological stations in the typical grassland area of Inner Mongolia. The correlation analysis was performed with the GIMMS NDVI3g vegetation index data. To understand the response of vegetation in typical grassland areas of Inner Mongolia to extreme climate changes. The results show that: In addition to CDD and FD0, all indexes showed an increasing trend before 2000 and a decreasing trend after 2000 . The CDD showed a continuous decrease trend, and FD0 decreased first and then increased. There was a significant positive correlation between NDVI and SDII and RX5D in extreme grassland areas in Inner Mongolia and a weak negative correlation with CDD. However, the correlation with the extreme temperature index is not obvious. The area where SU25 is
\end{abstract}

significantly negatively correlated with NDVI is larger, and TNn is obviously weakly negatively correlated. Therefore, it can be seen that extreme precipitation affects the dynamic change of vegetation in typical grassland areas more than extreme temperatures.

Keywords: extreme climate change;typical steppe;Inner Mongolia; correlation analysis

\section{摘要}

本文利用内蒙古典型草原区 19 个气象站 点的 1982-2015 年间的气温日数据和降水日数 据通过 RClimdex 模型提取极端气候指数, 并 对极端气候指数进行 Kriging 空间插值, 与 GIMMS NDVI3g 植被指数数据进行相关分析 来分析内蒙古典型草原区植被对极端气候变 化的响应情况。结果表明: 1982-1998年除 CDD 和 FD0 以外, 各指数均在 2000 年前呈增加趋 势, 2000 年后呈减少趋势。而 CDD 呈持续减 少趋势, FD0 则是先减少后增加趋势。内蒙古 典型草原区 NDVI 与极端降水指数中 SDII、 RX5D 呈极显著正相关, 与 CDD 呈弱负相关 关系。而与极端气温指数的相关性不明显, 其 中 SU25 与 NDVI 呈显著负相关的面积较大, $\mathrm{TNn}$ 呈明显的弱负相关。因此可知, 极端降水 比极端气温更加影响典型草原区的植被动态 
变化。

关键词: 极端气候变化, 典型草原, 内蒙古, 相关性分析

\section{1. 引言}

气候通常是指一个月以上时间内的天气 总和特征, 在统计意义上这个总和不仅包括平 均状态, 也反映出极端情况, 例如极端高温、 极端低温、寒潮、热浪、强降水、风貣风、持续 无雨期等 ${ }^{[1-2]}$ 。气候变化是人类面临的最大环 境事件之一, 全球变暖已是一个不争的事实 ${ }^{[3]}$ 。自上个世纪以来, 在全球变暖的大背景下, 极端气候事件变得更加频繁、更加普遍、更加 强烈。极端气候事件发生频率的加快以及发生 强度的加剧对生态环境和经济社会可持续发 展均构成了巨大挑战和严重威胁。与气温和降 水因素直接相关的极端气温事件和极端降水 事件的变化倍受科学家们的关注。就极端气温 事件而言, 20 世纪后半叶, 全球大部分陆地 地区低温、寒潮、霜冻、冷昼和冷夜等极端冷 事件发生频率逐渐减少, 而高温、热浪、暖昼 和暖夜等极端暖事件的发生频率呈显著增加 趋势, 其中, 极端冷事件频率的减少比极端暖 事件的增加更为明显, 导致陆地区域变暖更加 显著 ${ }^{[4-6]}$ 。极端降水方面, 全球雨日呈增加的 前提下, 陆地区域内各洲际、各国家乃至各地 区之间的变化特征差异显著, 但极端降水事件 对年总降水量的贡献一般呈增加趋势 ${ }^{[7-8]}$ 。

内蒙古典型草原是主要的草原类型, 因属 于温带内陆半干旱气候, 气温和降水变化幅度 较大, 因此也是一个对极端气候变化响应较为 敏感的地区。也是内蒙古牧区牧草主产草地类 型区, 因而典型草原区的植被状况直接对牧区 牧民的经济水平造成影响。植被是草原生态环 境保护大的重要屏障之一, 极端气候事件的频 发对植被的物候和生长发育等势必会产生一 定程度的影响, 进而可能引起植被覆盖状况的 下降, 影响区域净初级生产力等 ${ }^{[9-10]}$ 。因此, 本文结合内蒙古典型草原区植被指数数据, 进 一步了解极端气候事件对典型草原区植被的 影响特征, 为科学适应、减缓和应对典型草原 区气候异常和生态环境保护提供参考和依据, 促进牧区社会经济和生态环境的可持续发展。

\section{2. 数据与方法}

\section{1 研究区概况}

典型草原是温带内陆半干旱气候条件下 形成的草地类型, 主要代表性草本植物有羊 草、贝加尔针矛、大针茅、冰草、冷高以及黄 花苜宿等。我国典型草原主要分布于北纬 $35^{\circ} \sim 55^{\circ}$, 处于北半球中纬度接近内陆的地区。
主要分布于呼伦贝尔高原的西部, 锡林郭勒高 平原的大部分地区以及阴山北麓、大兴安岭南 部、西辽河平原等地。约占全国草地总面积的 $10.5 \%$ 。年均气温在 $-2^{\sim} 6^{\circ} \mathrm{C}$, 气温由东北向西 南递增, 冬季漫长严寒, 夏季短促闷热; 年降 水量在 $250^{\sim} 450 \mathrm{~mm}$ 之间, 由东南向西北递减, 降水集中在夏季, 春秋两季出现明显的旱期 [11-12]。典型草原是我国温带草原中一个有代表 性和典型性的一种类型, 是全球气温降水变化 幅度较大的地区。因此受极端气候的影响较 大, 因此开展内蒙古典型草原区植被对极端气 候变化响应的研究。

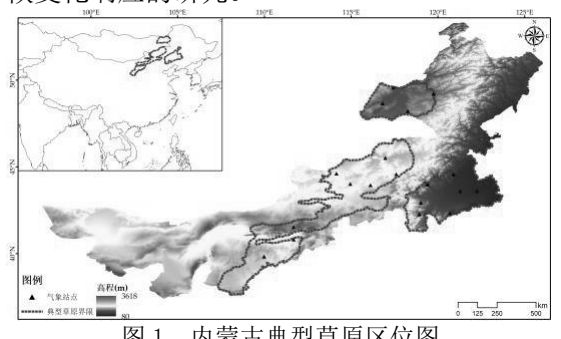

图 1.内蒙古典型草原区位图

\section{2 数据来源与处理}

\subsection{1 归一化植被指数月时序数据}

本文利用的归一化植被指数数据是被广 泛利用在长时间序列植被动态变化研究中的 由 NASA 提供的 GIMMS NDVI3g (https://nex. nasa.gov/nex/projects/1349) 数据集, 此数据空 间分辨率为 $8 \mathrm{~km}$, 时间分辨率为 15 天。本文 选取 1982-2015 年 (每年 4 月-10 月) 生长季 的 GIMMS NDVI3g 数据, 通过校正以及重采 样, 生成生长季月植被指数数据。

\subsection{2 极端气候指数数据}

本文数据来源于中国气象科学数据共享 服务网(CMDC), 依据各站点气象资料的连续 性及最长时段性等标准, 选取内蒙古典型草原 区内 19 个气象站点, 为匹配植被指数数据, 气象数据获取 1982-2015 年的日最高气温、 日最低气温、日平均气温和日降水量数据。各 站点气象数据均经过严格的质量控制处理, 包 括极值检验与时间一致性检验。然后基于 RClimDex 软件对获取的气象数据进行质量 控制, 如日最低气温是否大于日最高气温、异 常值与错误值篮选等。最终选取 4 个极端降水 指数与 4 个极端气温指数作为本研究的极端 气候指数, 具体看表 1 。 
表 1. 极端指数定义表

\begin{tabular}{|c|c|c|c|}
\hline 指数类型 & 指数 & 描述性名称 & 指数定义 \\
\hline \multirow{4}{*}{$\begin{array}{c}\text { 极端降水 } \\
\text { 指数 }\end{array}$} & CCD & 持续干燥指数（d） & 降水量 $<1 \mathrm{~mm}$ 的最大连续日数 \\
\hline & CWD & 持续湿润指数（d） & 降水量 $>=1 \mathrm{~mm}$ 的最大连续日数 \\
\hline & RX5D & 5 日最大降水 $(\mathrm{mm})$ & 每月内连续 5 天最大降水量 \\
\hline & SDII & 普通日降水强度 $(\mathrm{mm} / \mathrm{d})$ & 降水量 $>=1 \mathrm{~mm}$ 的总量与日数之比 \\
\hline \multirow{4}{*}{$\begin{array}{c}\text { 极端气温 } \\
\text { 指数 }\end{array}$} & SU25 & 夏日日数 $(\mathrm{d})$ & 年内日最高气温 $>25^{\circ} \mathrm{C}$ 的日数 \\
\hline & FD0 & 霜日日数（d） & 年内日最低气温 $<0^{\circ} \mathrm{C}$ 的日数 \\
\hline & TNn & 最低温度最小值 $\left({ }^{\circ} \mathrm{C}\right)$ & 日最低气温月最低值 \\
\hline & TXx & 最高温度最大值 $\left({ }^{\circ} \mathrm{C}\right)$ & 日最高气温月最高值 \\
\hline
\end{tabular}

1998 年是特大洪涝灾害年份, 所以各极端降 水指数趋势在 1998 年出现了一个峰值, 即各

\section{3 方法}

本文采用相关分析法研究 NDVI 与极端 气候因子之间的响应关系, 通过对各极端气候 指数 Kriging 空间插值后, 进行空间逐像元计 算生长季 NDVI 与对应的极端气候指数的相 关系数来反映内蒙古典型草原区植被生长状 况与极端气候因子之间的相关程度, 其计算公 式为:

$$
r=\frac{\sum_{i=1}^{n}(a-\bar{a})(a-\bar{b})}{\sum_{i=1}^{n}(a-\bar{a})^{2}(a-\bar{b})^{2}}
$$

式中: $n$ 为监测时间段的累计年数; $a 、 b$ 分 别为相关分析的 2 个变量; $\bar{a} 、 \bar{b}$ 为变量样本 值的平均值; 相关系数取值在 $[-1,1]$ 之间, 相 关系数的绝对值越大, 说明植被变化与气候因 子变化的相关性越高; 绝对值越小, 说明两者 的相关性越低 [13]。 $|\mathrm{r}|<0.3$ 为弱相关, $0.3<|\mathrm{r}|<0.5$ 为低度相关, $0.5<|\mathrm{r}|<0.8$ 为显著 相关, $0.8<|\mathrm{r}|<1$ 为极显著相关[14]。

\section{3. 结果与分析}

\section{1 植被指数与极端气候指数的变化趋势}

图 2 表示内蒙古典型草原区植被与极端 气候在 1982-2015 年间的变化趋势, 从 NDVI 变化趋势可以看出 1998 年是一个植被覆盖度 极高的一年, 达到 0.41。1982-1998 年 NDVI 呈增长趋势, 增长速率为 $0.0000894 / \mathrm{yr}$; 而 1998 年到 2015 年间呈减少趋势, 减少速率为 $-0.000025 / \mathrm{yr}$ 。同样, 各极端气候指数变化趋 势也在 1998 年或 1998 前后出现了转折, 由于
指数趋势的一个转折年份。内蒙古典型草原区 极端降水指数除持续干燥指数 CDD 以外均呈 现先增加后减少趋势, 1982-1998 年呈增加趋 势, 1998-2015 年呈减少趋势, 而 CDD 则呈 一直下降的趋势。这表明 1982-1998 年内蒙 古典型草原区降水量是增加的, 而从 1998-2015 年总降水量是减少的。极端降水指 数与内蒙古典型草原区植被指数的相关性较 大, 其中与降水强度 SDII 与连续 5 日最大降 水量 RX5D 指数存在极显著正相关, 相关性分 别达 0.7026 和 0.6517 。极端气温事件 1982-2015 年的变化趋势除了霜日数 FD0 以 外, 均呈现出先增加后减少, 而转折点在 2000 年前后。而 FD0 趋势则先减少, 后增加, 转 折点在 1998 年。极端气温指数与 NDVI 间的 相关性呈弱负相关 (表 2)。而极端降水指数 和极端气温指数间, SDII 与 $\mathrm{TXx}$ 在 $\mathrm{p}<0.01$ 的 水平上呈负相关, 与 $\mathrm{TNn}$ 在 $\mathrm{p}<0.05$ 的水平上 呈正相关; RX5D 与 TXx 和 SU25 分别在 $\mathrm{p}<0.001$ 和 $\mathrm{p}<0.01$ 的水平上呈负相关。
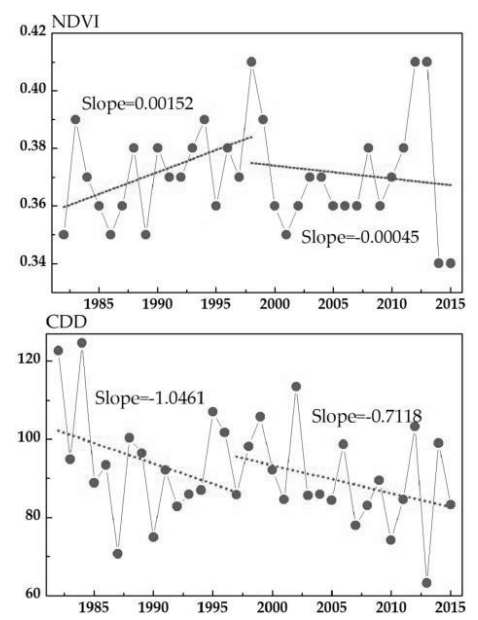

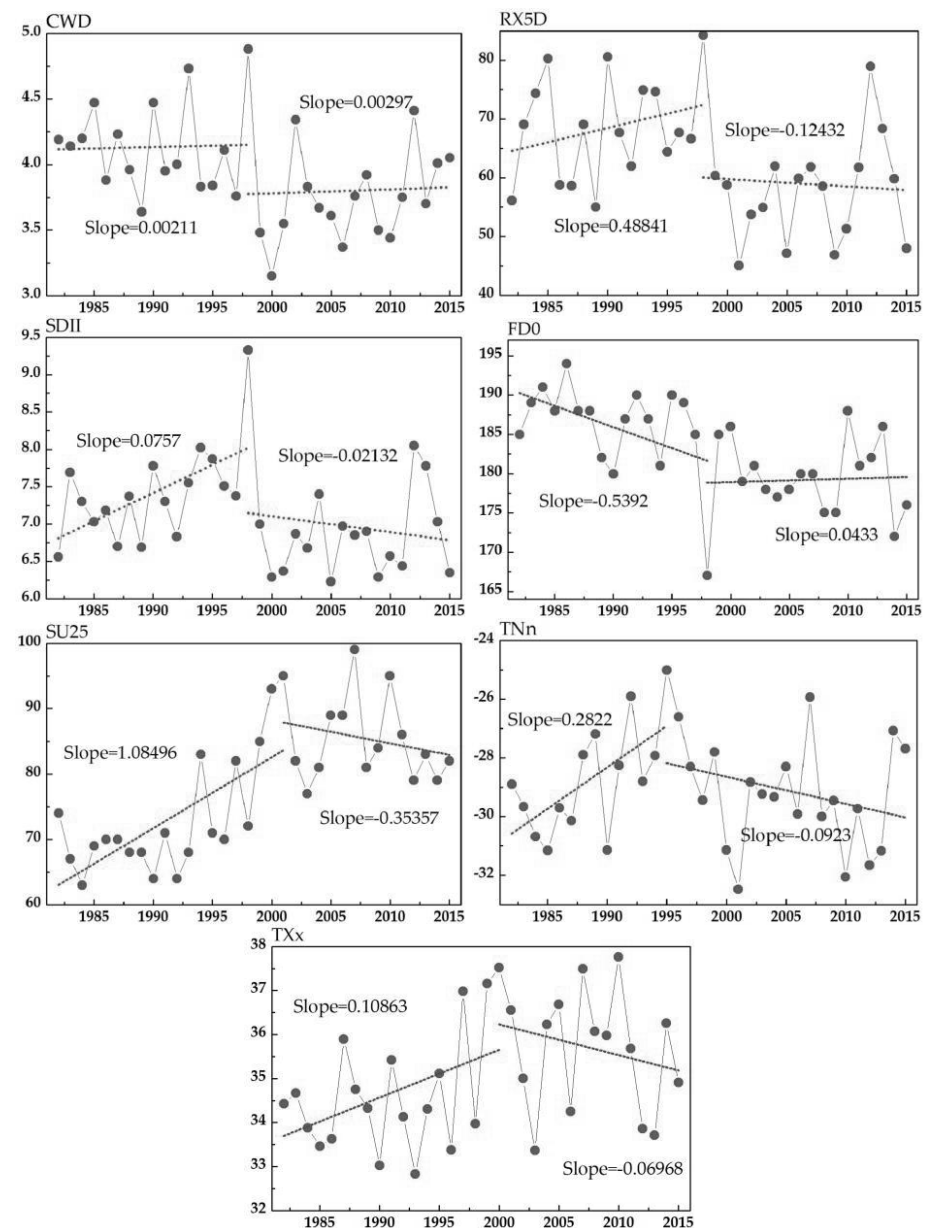

图 2. 内蒙古典型草原区 NDVI 与极端气候变化趋势

表 2. 各指数间的相关系数

\begin{tabular}{|c|c|c|c|c|c|c|c|c|c|}
\hline & NDVI & CDD & CWD & SDII & RX5D & TXX & $\mathrm{TNn}$ & SU25 & FD0 \\
\hline NDVI & 1 & -- & -- & -- & -- & -- & -- & -- & -- \\
\hline CDD & -0.1135 & -- & -- & -- & -- & - & -- & -- & - \\
\hline CWD & 0.2959 & 0.1894 & -- & -- & - & - & -- & -- & -- \\
\hline SDII & $0.7026^{* * *}$ & 0.126 & $0.5759^{* * *}$ & -- & -- & -- & -- & -- & -- \\
\hline RX5D & $0.6517^{* * *}$ & 0.1058 & $0.6434^{* * *}$ & $0.8269^{* * *}$ & -- & - & -- & -- & -- \\
\hline $\mathrm{TXx}$ & -0.2777 & -0.1785 & $-0.6336^{* * *}$ & $-0.4712^{* *}$ & $-0.5428^{* * *}$ & -- & -- & -- & -- \\
\hline TNn & -0.22149 & 0.2092 & -0.0033 & $0.0505^{*}$ & -0.0779 & 0.0235 & -- & -- & -- \\
\hline SU25 & -0.1318 & -0.2844 & $-0.6491^{* * *}$ & -0.4225 & $-0.5263^{* *}$ & $0.7195^{* * *}$ & -0.1863 & - & -- \\
\hline FD0 & -0.0081 & 0.1267 & -0.0366 & -0.0429 & 0.1562 & -0.1835 & 0.0245 & $-0.3761^{* *}$ & 1 \\
\hline
\end{tabular}

注: “***”、“**”和“*”分别表示 $\mathrm{p}<0.001, \mathrm{p}<0.01$ 和 $\mathrm{p}<0.05$.

\subsection{NDVI 与极端气候指数的空间相关性分析}

图 3 表示内蒙古典型草原区各极端气候 指数与植被指数之间的空间逐像元相关性, 从 图中可以看出, 极端降水指数中的 RX5D、SDII
与 NDVI 的相关性较高, 呈显著正相关, 与 CDD 则呈负相关关系。这与实际意义较为符合, 说 明降水量与植被指数呈正相关关系。而整个典 
型草原区域西南部 NDVI 与各指数间呈现较弱 的负相关关系, 然而这与纬度的变化与土壤类 型的变化密切相关。极端气温指数中中部地区 的夏日日数 SU25 与植被指数呈极显著负相关 的像元面积较大, 区域的西南部分呈现出显著
正相关; 霜日日数 FD0、最高气温月最大值 TXx 与 NDVI 的相关性在区域的西南部分呈显 著负相关, 中部和东北部呈弱正相关, 而最低 气温月最低值 TNn 与 NDVI 呈负相关的像元面 积较大。

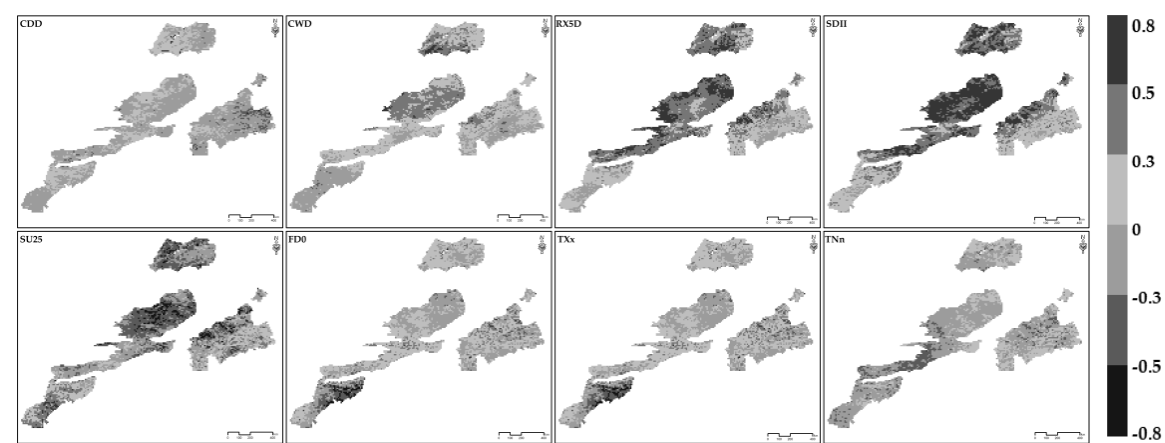

图 3. 内蒙古典型草原区各极端气候指数与 NDVI 间的逐像元空间相关性

\section{4. 结论}

本文通过研究内蒙古典型草原区植被对 极端气候事件的响应, 得出以下结论:

在时间上, 内蒙古典型草原区 1982-1998 年 NDVI 呈增长趋势，而 1998 年到 2015 年间 呈减少趋势。极端降水指数除持续干燥指数 CDD 以外均呈现先增加后减少趋势, 19821998 年呈增加趋势, 1998-2015 年呈减少趋 势, 而 CDD 则呈一直下降的趋势。极端降水指 数与内蒙古典型草原区植被指数的相关性较 大, 其中与降水强度 SDII 与连续 5 日最大降 水量 RX5D 指数存在极显著正相关。极端气温 事件 1982-2015 年的变化趋势除了霜日数 FD0 以外, 均呈现出先增加后减少。而 FD0 趋势则 先减少, 后增加, 转折点在 1998 年。极端气 温指数与 NDVI 间的相关性呈弱负相关。在空 间上, 同样是极端降水指数中的 SDII、RX5D 与 NDVI 的相关性较强, 呈极显著正相关, 而 $\mathrm{CDD}$ 成弱负相关。与极端气温指数的相关性不 明显, 其中 SU25 与 NDVI 呈显著负相关的面积 较大, TNn 呈明显的弱负相关。因此, 极端降 水比极端气温更加影响典型草原区的植被动 态变化。

\section{Acknowledgements}

This study was supported by the National Science Foundation of China (41571491 and 41371495); The China Special Fund for Meteorological Research in the Public Interest (GYHY201506001-6); The National Key Technology R\&D Program of China under Grant
(2013BAK05B01); The Fundamental Research Funds for the Central Universities of China (2412016KJ046).

\section{致谢}

本研究得到了国家自然科学基金项目 (41571491 和 41371495)、公益性行业 (气象) 科研重大专项(GYHY201506001-6)、国家重点 技术研发项目（2013BAK05B01）、中央高校 基本科研业务费专项资金资助 (2412016KJ046)

通讯作者：张继权（1965- ), 教授, 博士生 导师, 主要从事环境灾害风险评价与管理等方 向研究。邮箱: zhangjq022@nenu. edu. cn

\section{参考文献}

[1] 任国玉, 封国林, 严中伟.中国极端气候变 化观测研究回顾与展望.气候与环境研究, 2010, 15 (4): 337-353.

[2] 钱维宏, 符娇兰, 张玮玮, 等.近 40 年中 国平均气候与极值气候变化的概述. 地球科 学进展, 2007, 22 (7): 673-684.

[3] IPCC. Managing the Risks of Extreme Events and Disasters to Advance Climate Change Adaptation. A Special Report of Working Groups I and II of the Intergovernmental Panel on Climate Change. C.B., Barros, V., Stocker, T.F., Qin, D., et al. 
Cambridge, UK, and New York, NY, USA: Cambridge University Press, 2013.

[4] Deng Haijun, Chen Yaning, Shi Xun, et al. Dynamics of temperature and precipitation extremes and their spatial variation in the arid region of northwest China. Atmospheric Research, 2014, 138:346-355.

[5] Rao B.Bapuji, Chowdary P. Santhibhushan, Sandeep V.M., et al. Rising minimum temperature trends over India in recent decades: Implications for agricultural production. Global and Planetary Change, 2014, 117:1-8.

[6] Lima Isabel M. P.de, Santo Fátima Espírito, Ramos Alexandre M., et al. Recent changes in daily precipitation and surface air temperature extremes in mainland Portugal, in the period 1941-2007. Atmospheric Research, 2013, 127:195-209.

[7] Wen Guanhuan, Huang Gang, Tao Weichen, et al. Observed trends in light precipitation events over global land during 1961-2010. Theoretical and Applied Climatology, 2015, 125:161-173.

[8] Keggenhoff Ina, Elizbarashvili Mariam, Amiri-Farahani A., et al. Trends in daily temperature and precipitation extremes over Georgia, 1971-2010. Weather and Climate Extremes, 2014, 4:75-85.

[9] Gornall Jemma, Betts Richard, Burke Eleanor, et al. Implications of Climate Change for Agricultural Productivity in the Early Twenty-first Century. Philosophical Transactions of the Royal Society B: Biological Sciences, 2010, 365 (1554): 29732989.

[10] Zhang R, Zou H, Hong M, et al. Risk analysis of water resources crisis in the lancang-mekong river drainage basin under the background of climate change. Journal of Risk Analysis and Crisis Response, 2012, 2(3):209-213.

[11] 陈效述, 郑婷. 内蒙古典型草原地上生物 量的空间格局及其气候成因分析. 地理科
学, 2008, 28(3):369-374.

[12] Zhang Q, Yu H, Liu G, et al. The Response Characteristics of Xilingol Grassland to Uneven Distribution of Precipitation at Temporal and Spatial Scale[C]// Meeting of Risk Analysis Council of China Association for Disaster Prevention. 2016:206.

[13] 王强, 张勃, 戴声佩, 等. 三北防护林工 程区植被覆盖变化与影响因子分析. 中国 环境科学, 2012, 32 (7): 1302-1308.

[14] 索玉霞, 王正兴, 刘闯, 等. 中亚地区 1982-2002 年植被指数与气温和降水的相 关性分析. 资源科学, 2009, 31 (8): 1422-1429. 